\title{
PAX2 mutations in renal-coloboma syndrome: mutational hotspot and germline mosaicism
}

\author{
Jeanne Amiel ${ }^{1}$, Sophie Audollent ${ }^{1}$, Dominique Joly ${ }^{2}$, Pascal Dureau ${ }^{3}$, Rémi Salomon ${ }^{2}$,

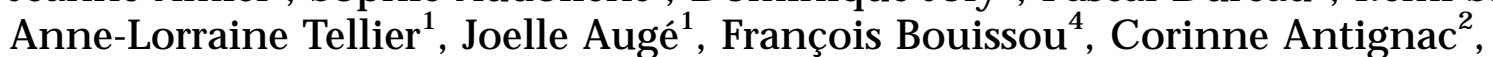 \\ Marie-Claire Gubler ${ }^{2}$, Michel R Eccles ${ }^{5}$, Arnold Munnich ${ }^{1}$, Michel Vekemans $^{1}$, \\ Stanislas Lyonnet ${ }^{1}$ and Tania Attié-Bitach ${ }^{1}$
}

\begin{abstract}
${ }^{1}$ Département de Génétique et Unité IN SERM U-393; ${ }^{2}$ Département de N éphrologie et Unité INSERM U-423; ${ }^{3}$ Service d'Ophtalmologie, Hôpital Necker-Enfants Malades, Paris; ${ }^{4}$ Unité de Néphrologie Pédiatrique, Hôpital des enfants, Toulouse; ${ }^{5}$ Cancer Genetics Laboratory, Department of Biochemistry, University of Otago, Dunedin, New Zealand
\end{abstract}

The renal-coloboma syndrome (RCS, MIM 120330) is an autosomal dominant disorder caused by PAX2 gene mutations. We screened the entire coding sequence of the PAX2 gene for mutations in nine patients with RCS. We found five heterozygous PAX2 gene mutations: a dinucleotide insertion (2G) at position 619 in one sporadic RCS case, a single nucleotide insertion $(619+G)$ in three unrelated cases, and a single nucleotide deletion in a familial case. In this familial case, three affected sibs showed a striking ocular phenotypic variability. Each of the sibs carried a 619insG mutation, whilst unaffected parents did not, suggesting the presence of germline mosaicism. Interestingly, the 619insG mutation has been previously reported in several patients and is also responsible for the Pax ${ }^{1 \mathrm{Neu}}$ mouse mutant, an animal model of human RCS. This study confirms the critical role of the PAX2 gene in human renal and ocular development. In addition, it emphasises the high variability of ocular defects associated with PAX2 mutations ranging from subtle optic disc anomalies to microphthalmia. Finally, the presence of PAX2 germline mosaicism highlights the difficulties associated with genetic counselling for PAX2 mutations. European Journal of Human Genetics (2000) 8, 820-826.

Keywords: PAX2; renal-coloboma syndrome; germline mosaicism; mutational hotspot

\section{Introduction}

In humans, PAX gene mutations are responsible for Waardenburg syndrome typel and III $\left(P A X 3^{1}\right)$, aniridia and Peter's anomaly $\left(\mathrm{PAX} 6^{2-4}\right)$, thyroïd dysgenesis $\left(\mathrm{PAX} 8^{5}\right)$, oligodontia $\left(\mathrm{PAX} 9^{6}\right)$ and renal-coloboma syndrome (RCS, PAX $\left.2^{7}\right)$. RCS is a rare autosomal dominant disorder (MIM 120330) associating optic nerve coloboma and retinal epithelium thinning, renal hypoplasia, vesico-ureteral reflux and mild sensorineural hearing loss. In 1995, Sanyanusin et al first reported a PAX 2 mutation in patients with renal and ocular defects. ${ }^{7}$ Since then, eight different PAX 2 mutations and a chromosome10/13 de novo translocation have been identified in 13 unrelated patients. ${ }^{7-14}$ It has been shown that PAX 2 gene

Correspondence: Tania Attié-Bitach, Département de Génétique et Unité INSERM U-393; Hôpital Necker-Enfants Malades, 149 rue de Sèvres, 75743 Paris, Cedex 15, France. Tel: + 331444949 82; Fax: +33 1444951 17; E-mail: tania.attie@necker.fr

Received 28 January 2000; revised 20 June 2000; accepted 21 June 2000 mutations are associated with both inter and intrafamilial phenotypic variability; all patients share renal and ocular abnormalities, while some present with hearing loss, mental retardation or seizures. ${ }^{9}$ Several Pax2 mutant mice are known: Pax2 ${ }^{1 \mathrm{Neu}}$ resulting from a Pax2 frameshift mutation, ${ }^{15}$ Krd carrying a large chromosomal deletion encompassing the Pax2 gene (kidney and retinal defect, ${ }^{16}$ ), and the Pax2 knock-out mouse. ${ }^{17,18}$ All the mouse mutants have kidney and optic nerve or retinal defects.

Here we report the identification of PAX 2 mutations in five out of nine unrelated RCS patients, and two are previously undescribed mutations. In one familial case, unaffected parents did not carry the mutation suggesting the presence of germline mosaicism involving the paternal allele. The finding that the G619 insertion has occurred three times independently in our series as well as in seven other cases of RCS, and that we have also observed a novel 619insGG 
suggests the existence of a poly $\mathrm{G}$ mutational hot-spot of the PAX 2 gene.

\section{Materials and methods Patients and families}

A total of nine patients with renal abnormalities and coloboma were studied for PAX 2 mutations. Table 1 summarises the clinical features of the patients.

\section{Detection of PAX2 mutations and large deletion}

Genomic DNA was extracted from peripheral blood samples using standard protocols. PCR was carried out using intronic primers for the 12 exons of the PAX 2 gene. ${ }^{19}$ PCR products were labelled by incorporation of ${ }^{33} \mathrm{PdCTP}$. Direct DNA sequencing of exon 2 to 5 was performed for all patients. Single-strand conformation polymorphism (SSCP) was used for the other exons to detect nucleotide variation according to standard conditions (MDE gel (Bioproducts, Rockland, $M E, U S A)$, electrophoresis overnight at room temperature and at $4 \mathrm{~W}$, autoradiography $48 \mathrm{~h}$ ). Direct DNA sequencing was performed when an abnormal SSCP pattern was detected using the Dye Deoxy Terminator Cycle Sequencing kit (PE Biosystems, Warrington, UK). In addition, an intragenic (AC)n highly polymorphic dinucleotide repeat ${ }^{7}$ was studied in all patients to rule out large deletions. Karyotype and FISH analysis was performed in the patient uninformative for the CA repeat.

\section{Results}

We screened the entire coding sequence of the PAX 2 gene for mutations in RCS patients and report 3 different PAX 2 mutations (Figure1) in five unrelated RCS patients with variable ocular findings. Table 1 summarises the phenotype of all the patients and the mutations identified.
A previously not described PAX2 gene mutation (a dinucleotide insertion GG at position 619) was identified in an isolated RCS case showing bilateral optic nerve coloboma and bilateral renal hypoplasia (patient NI). This frameshift mutation predicts a premature termination of the protein 3 codons downstream from the mutation (Figure1A and 1C). The mother did not carry the mutation but the healthy father was not available for DNA study.

A single nucleotide insertion ( $G$ ) at position 619 was found in an isolated case with bilateral renal hypoplasia associated with bilateral microphthalmia and retinal degeneration (patient RA, Figure 3A). I rides were normal. Parents were not available for DNA study. As with the previous mutation, the 619insG frameshift mutation predicts a premature termination of the protein 27 codons downstream from the insertion. The same mutation was identified in a sporadic case with bilateral renal hypoplasia associated with bilateral retinal coloboma (patient PE, Figure $1 \mathrm{~A}$ and $1 \mathrm{~B}$ ). Parents were studied and did not carry the mutation suggesting the presence of a de novo mutation.

A family with three affected sibs were studied (patients AR, Figure2). Patient III had bilateral renal hypoplasia and a 'morning-glory syndrome' (equivalent to an optic coloboma), whilst II2 and II3 presented with isolated unilateral cystic renal hypoplasia with no ocular manifestation. Careful ophthalmological examination showed an optic disc anomaly in both of them: bilateral papillary dysplasia in 112 (Figure 3B) and bilateral optic nerve coloboma in II3 (Figures $3 C$ and 3D). A 619insG was identified in all three children of this family. Both unaffected parents did not carry the mutation, however, suggesting a germline mosaicism (Figure2). The study of a PAX2 intragenic DNA microsatellite marker showed that the mutation was of paternal origin. False paternity was excluded by the study of polymorphic markers.

Table 1 Clinical features and PAX2 mutations observed in RCS patients

\begin{tabular}{|c|c|c|c|}
\hline Case & Clinical features & $\begin{array}{l}\text { Nature of } \\
\text { mutation }\end{array}$ & $\begin{array}{l}\text { Familial (F) } \\
\text { Isolated (I) } \\
\text { /Inheritance }\end{array}$ \\
\hline $\mathrm{NI}$ & Bilateral renal hypoplasia and bilateral optic nerve coloboma & 619insGG & $\mathrm{l} / \mathrm{T}$ \\
\hline RA & Bilateral renal hypoplasia and bilateral microphthalmia with right optic nerve dysplasia & 619insG & $\mathrm{l} / ?$ \\
\hline PE & Bilateral renal hypoplasia and bilateral retinal coloboma & 619insG & I/de novo \\
\hline AR & $\begin{array}{l}\text { II1 - Bilateral renal hypoplasia, 'morning glory syndrome' } \\
\text { II2 - Unilateral renal hypoplasia and bilateral papillary dysplasia } \\
\text { II3 - Unilateral renal hypoplasia, bilateral papillary coloboma }\end{array}$ & 619insG & $\begin{array}{l}\text { F/germline } \\
\text { mosaicism }\end{array}$ \\
\hline MA & $\begin{array}{l}\text { 1. Unilateral renal agenesis, bilateral optic nerve coloboma and severe myopia } \\
\text { 2. Renal insufficiency, slight reduction in kidney size and bilateral optic nerve coloboma }\end{array}$ & 832delG & F/inherited \\
\hline BA & $\begin{array}{l}\text { Bilateral renal hypoplasia in one sib, bilateral renal hypoplasia, vesico-ureteral reflux and } \\
\text { unilateral microphthalmia with iris coloboma in one sib }\end{array}$ & - & $\mathrm{F}$ \\
\hline $\mathrm{PH}$ & Bilateral renal hypoplasia and coloboma & - & I \\
\hline VE & Single pelvic kidney, bilateral retinal coloboma and microphthalmia & - & I \\
\hline
\end{tabular}


A

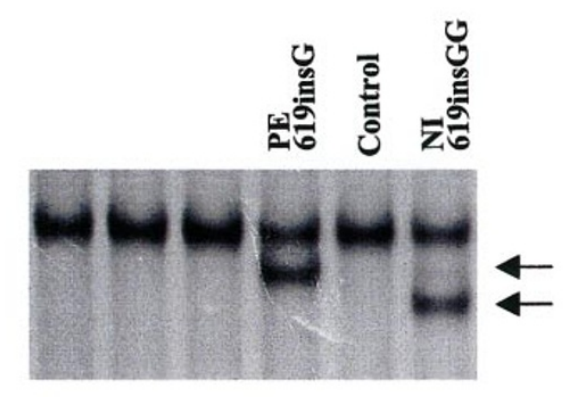

B

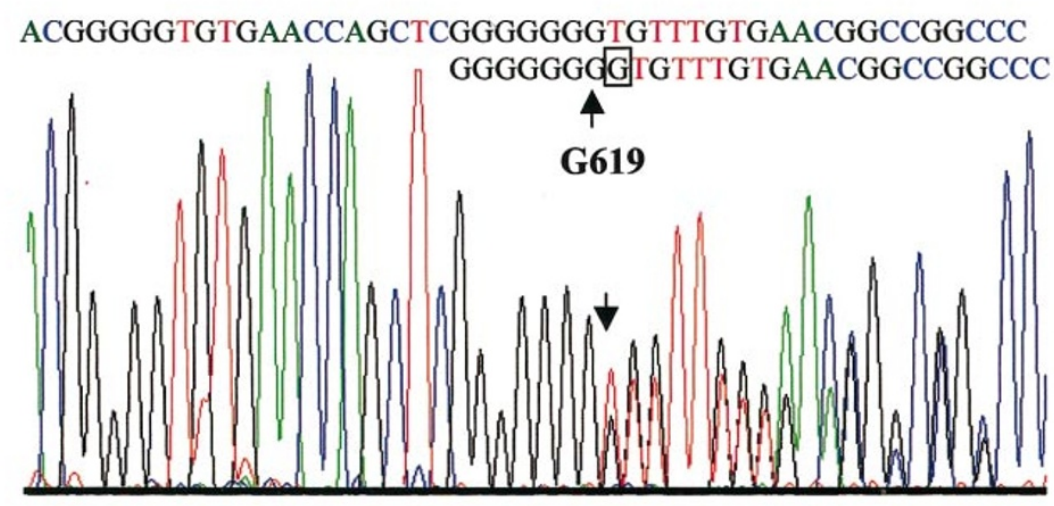

C

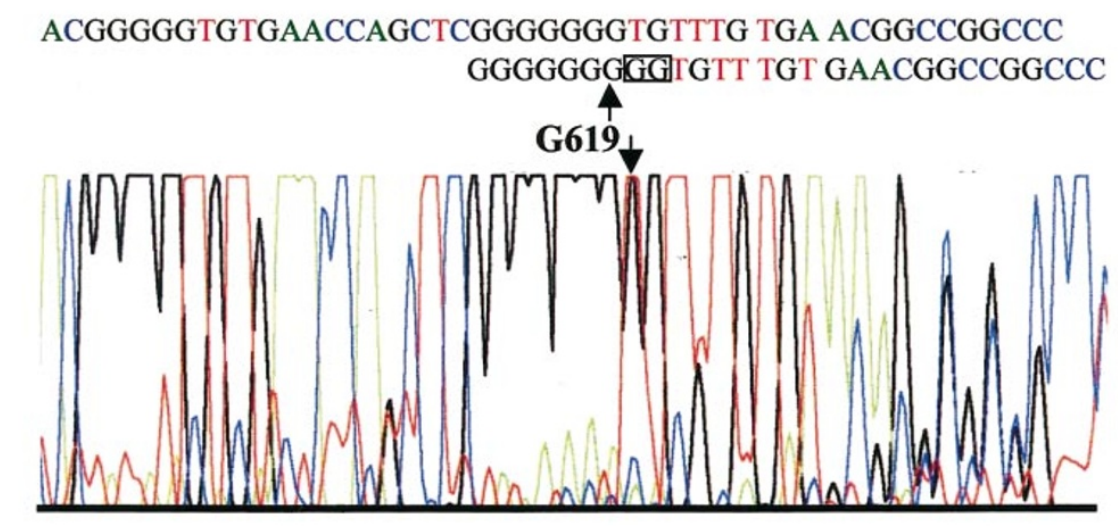

Wild type 619insGG

Wild type 619insG

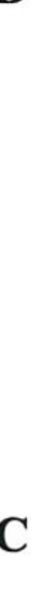




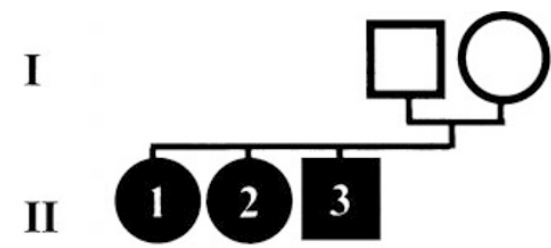

A

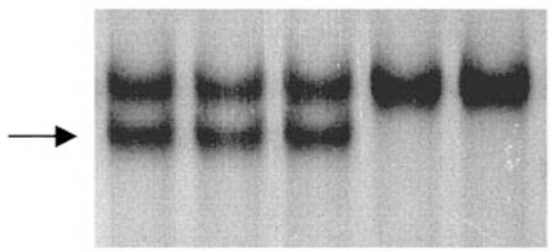

B

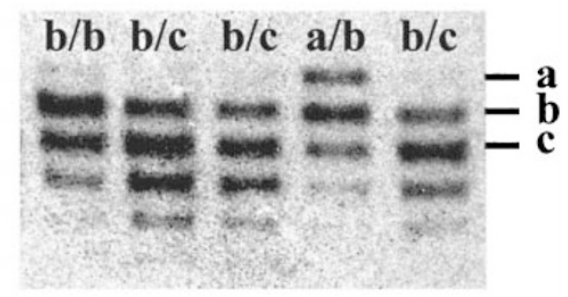

II1 II2 II3

Figure 2 SSCP (A) and PAX2 intragenic polymorphic marker analysis (B) in the family AR. The abnormal SSCP band indicated by an arrow is seen only in the three affected children. In $\mathrm{B}$, the three affected children share a common paternal allele (b), whilst the maternal allele is either $b$ (patient II1) or c (patients II2 and II3) thus suggesting a paternal germline mosaicism.

Finally, we identified a single $G$ deletion at position 832 in exon 3 of the PAX2 gene (Patient MA, Figure1D). This mutation was identified in a family where a child presented bilateral optic nerve coloboma, severe myopia and unilateral renal agenesis, whilst his father had bilateral optic nerve coloboma with association to a chorioretinal coloboma (Figures3E and 3F). Renal explorations in the father showed renal insufficiency and slight reduction in kidney size. The 832delG frameshift mutation predicts a premature termination of the protein 61 codons downstream from the deletion and has not been reported previously.

None of these mutations was observed in a panel of 100 control chromosomes.

Finally, the PAX 2 intragenic microsatellite marker study showed the presence of two alleles in all patients except one. In this patient, a karyotype and FISH analysis indicated that both copies of the PAX 2 gene were present. Thus, in all patients tested, no evidence of a large PAX2 gene deletion could be found.

\section{Discussion}

The PAX genes comprise a family of developmental genes encoding nuclear transcription factors. ${ }^{20}$ They are charac- terised by a conserved amino acid motif with DNA binding activity, the paired domain. Nine members of this family have been isolated in human and mouse, and classified into four groups sharing structural motifs (ie octapeptide and homeodomain) and sequence similarities. Disruption of at least five PAX genes has been shown to result in developmental abnormalities in humans. ${ }^{1-7}$ So far, eight different PAX2 mutations have been reported in 13 patients with RCS. $^{7-13}$ In all previously reported cases, patients presented with RCS or renal hypoplasia with mild ocular manifestations described as optic disc dysplasia or papillo-renal syndrome. Here, we report on five additional cases of PAX2 mutations in patients with RCS. One novel mutation resulted from a 2 guanine nucleotides insertion within a stretch of 7 guanines in exon 2 of the PAX 2 gene. In three other patients, a single $\mathrm{G}$ insertion at the same position has been identified. This latter mutation has al ready been reported in several patients. Finally, we identified a novel guanine deletion at position 832 in a familial RCS. Wefailed, however, to find either a PAX 2 mutation or a large deletion in 4/9RCS patients examined. Although the promotor region as well as the non-coding sequences of the PAX 2 gene have not yet been studied, these results suggest that the RCS might be genetically heterogeneous.

Interestingly, in one familial case, a paternal germline mosaicism was observed. Furthermore, in this family, the clinical spectrum was quite variable with ocular anomalies being detected only after careful ophthalmological examination in two out of three sibs. This observation confirms findings of previous studies showing that all patients with PAX 2 mutations present with an abnormal eye fundus, even a very subtle one.

Along with the mutations reported here and unpublished data (Salomon et al, 2000 personal communication), 11 different PAX 2 mutations have been hitherto identified in 20 unrelated patients. They are summarised in Figure 4. In addition, a 10/13translocation within either intron 3 or 4 of the PAX 2 gene has been reported. ${ }^{14}$ With the exception of two mutations in exons5 and 7, all PAX2 gene mutations reported so far are located in the paired domain (exons 2 and 3). Interestingly, 17/20 mutations are frameshift mutations predicting a truncated and non-functional PAX2 protein lacking the transactivation domain, the homeodomain or the octapeptide. Therefore, haplo-insufficiency is the most likely mechanism of dominance of PAX 2 mutations in humans. Finally, 12/20 PAX 2 gene mutations are either a deletion or an insertion of one or two Gs at position 619 in a stretch of $7 \mathrm{Gs}$ which could be regarded as a mutational hot spot resulting from polymerase slippage. Interestingly, the PAX $2^{1 \text { Neu }}$ mutant mouse has been shown to carry the same $G$ insertion at the very same position. Therefore this mouse mutant represents a natural mouse model for PAX 2 mutations in humans. ${ }^{15}$

In conclusion, our study confirms the critical role of the PAX2 gene in human renal and ocular development, and 

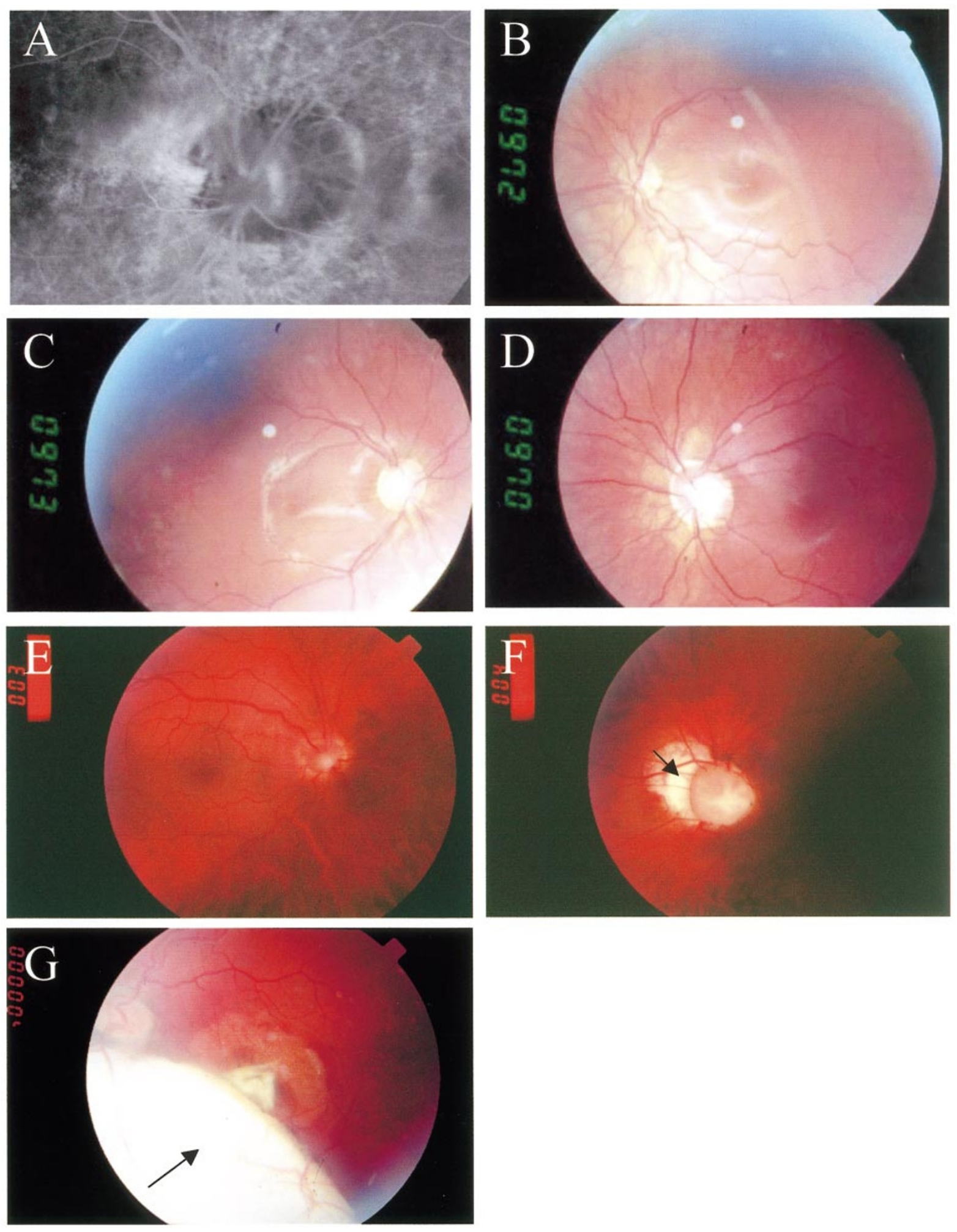

Figure 3 Ophthalmological examination of the patients. A: fluorescein angiography centered on the optic nerve of the right eye of patient RA showing papillary dysplasia. Family AR: fundus of the left eye of patient II2 (B) showing papillary dysplasia with abnormal vessels division; right (C) and left (D) fundus of patient II3 showing bilateral optic nerve coloboma. Patient MA: right (E) and left (F) fundus showing bilateral optic nerve coloboma, more severe in the left eye with the association to a chorioretinal coloboma (arrow). G: Left eye fundus of patient TH showing a large nasal inferior chorioretinal coloboma (arrow). 


\section{1delT

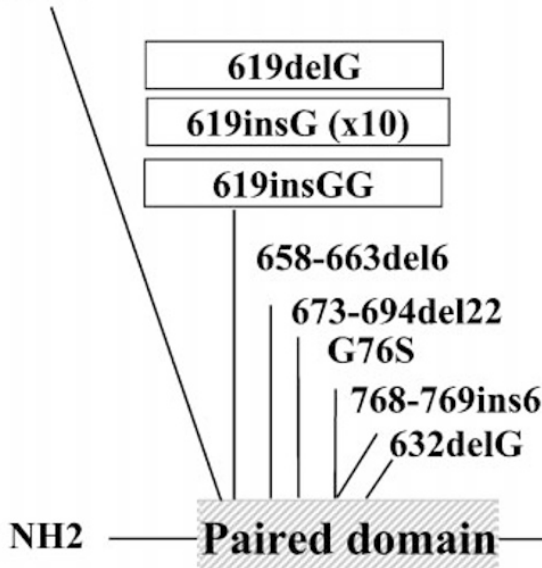 \\ NH2}

\begin{tabular}{|c|c|c|}
\hline PAX2 Mutation & Inheritance (cases) & Reference \\
\hline Translocation & de novo & Narahara, 1997 \\
\hline 611delT & I, unknown & Cunliffe, 1998 \\
\hline 619delG & I, unknown & Schimmenti, 1999 \\
\hline 619insG & $\begin{array}{l}\mathrm{F} \\
\mathrm{F}(1) ; \\
\text { de novo }(1) \\
\mathrm{F} \\
\mathrm{I} \text {, unknown } \\
\text { de novo }(2) \\
\text { de novo }(1) ; \\
\mathrm{F} \text {, germline mosaicism (1) } \\
\mathrm{I} \text {, unknown (1) }\end{array}$ & $\begin{array}{l}\text { Sanyanusin, } 1995 \mathrm{~b} \\
\text { Schimmenti, } 1997 \\
\text { Schimmenti, } 1999 \\
\text { Porteous, } 2000 \\
\text { Salomon, } 2000 \text { pers comm } \\
\text { This report }\end{array}$ \\
\hline 619insGG & I, unknown & This report \\
\hline 658del6 & de novo & Salomon, 2000 pers comm \\
\hline 673-694del22 & de novo & Schimmenti, 1997 \\
\hline 768-769ins6 & I, unknown & Devriendt, 1998 \\
\hline G75S & $\mathrm{F}$ & Devriendt, 1998 \\
\hline $832 \mathrm{delG}$ & $\mathrm{F}$ & This report \\
\hline $1104 \mathrm{delC}$ & $\mathrm{F}$ & Sanyanusin, 1995a \\
\hline $\mathrm{R} 252 \mathrm{X}$ & $\mathrm{F}$ & Porteous, 2000 \\
\hline
\end{tabular}

\section{R252X}

1104delC

OP

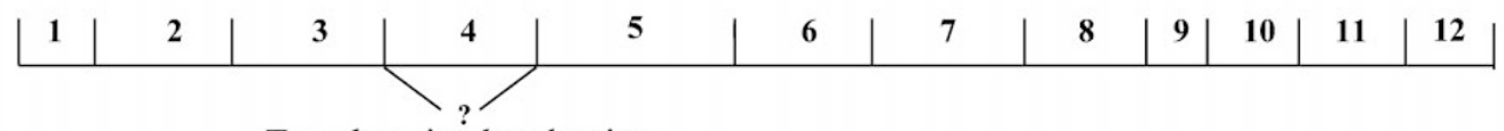

Translocation breakpoint

Figure 4 Human PAX2 mutations, F: familial; I: isolated.

further demonstrates the wide variation in the clinical spectrum of patients who have PAX2 mutations. PAX2 mutations are responsible for causing renal hypoplasia associated with various ocular manifestations ranging from subtle optic disc anomalies to microphthalmia. In addition, we describea novel insertion in a mutational polyG hot spot. This type of mutation represent $60 \%$ of PAX 2 mutations reported so far (12/20). Finally, the presence of PAX2 germline mosaicism in one family makes genetic counselling difficult in RCS.

\section{Acknowledgements}

We thank Drs A Bensman, M Broyer, P Cochat, DF Ferraz, J Kaplan, C Loirat, $H$ Plauchu and L Yver for referring patients; M rs JM Lacassin and $L$ Lesueur for fundus pictures of family $A R$, Drs $B$ Roussel and $M$ Talmud for fundus pictures of patient TH; and Drs M Prieur, P Gosset and S Romana for chromosomal analysis. This study was supported by the association IMAGE. ALT is a recipient of a fellowship from the Fondation Guigoz.

\section{References}

1 Baldwin CT, Hoth CF, Amos JA, da-Silva EO, Milunsky A: An exonic mutation in the HuP2 paired domain gene causes Waardenburg's syndrome. Nature 1992; 355: 637-638.
2 Jordan T, Hanson I, Zaletayev D et al: The human PAX 6 gene is mutated in two patients with aniridia. Nat Genet 1992; 1: 328-332.

3 Glaser T, Walton D, Maas R: Genomic structure, evolutionary conservation and aniridia mutations in the human PAX 6 gene. Nat Genet 1992; 2: 232-238.

4 Hanson I, Fletcher J, Jordan T et al: Mutations at the PAX 6 locus are found in heterogeneous anterior segment malformations including Peter's anomaly. Nat Genet 1994; 6: 168-173.

5 Macchia P, Lapi P, Krude H et al: PAX 8 mutations associated with congenital hypothyoidism caused by thyroid dysgenesis. Nat Genet 1998; 19: 83-86.

6 Stockton DW, Das P, Goldenberg M et al: Mutation of PAX9 is associated with oligodontia. Nat Genet 2000; 24: 18-19.

7 Sanyanusin P, Schimmenti L, McNoe L et al: Mutations of the PAX2 gene in a family with optic nerve colobomas, renal anomalies and vesico-ureteral reflux. Nat Genet 1995; 9: 358-363.

8 Sanyanusin P, McNoeL, Sullivan M, Weaver R, Eccles M: Mutation of PAX 2 in two siblings with renal-coloboma syndrome. Hum Mol Genet 1995; 4: 2183-2184.

9 Schimmenti L, Cunliffe H, McNoe L et al: Further delineation of renal-coloboma syndrome in patients with extreme variability of phenotype and identical PAX2 mutations. Am J Hum Genet 1997; 60: 869-878.

10 Devriendt K, Matthijs G, Van Damme B et al: Missense mutation and hexanucleotide duplication in the PAX2 gene in two unrelated families with renal-coloboma syndrome. Hum Genet 1998; 103: 149-153. 
11 Cunliffe H, McNoe L, Devriendt K, Brunner H, Eccles M: The prevalence of PAX2 mutations in patients with isolated colobomas associated with urogenital anomalies. J Med Genet 1998; 35: 806-812.

12 Schimmenti LA, Shim HH, Wirtschafter JD et al: Homonucleotide expansion and contraction mutations of PAX 2 and inclusion of chiari 1 malformation as part of renal-coloboma syndrome. Hum Mutat 1999; 14: 369-376.

13 Porteous S, Torban E, Cho NP et al: Primary renal hypoplasia in humans and mice with PAX2 mutations: evidence of increased apoptosis in fetal kidneys of PAX $2^{1 \mathrm{Neu}}+/-$ mutant mice. Hum $\mathrm{Mol}$ Genet 2000; 9: 1-11.

14 Narahara K, Baker E, Ito S et al: Localisation of a 10q breakpoint within the PAX2 gene in a patient with a de novo $t(10-13)$ translocation and optic nerve coloboma-renal disease. J M ed Genet 1997; 34: 213-216.

15 Favor J, Sandulache R, Neuhaüser-Klauss A et al: The mouse Pax $2^{1 \mathrm{Neu}}$ mutation is identical to a human PAX2 mutation in a family with renal-coloboma syndrome and results in developmental defects of the brain, ear, eye, and kidney. Proc Natl Acad Sci USA 1996; 93: 13870-13875.
16 Keller S, Jones J, Boyle A et al: Kidney and retinal defects (Krd), a transgene-induced mutation with a deletion of mouse chromosome19 that includes the Pax2 locus. Genomics 1994; 23: 309-320.

17 Torres M, Gomez-Pardo E, Dressler G, Gruss P: Pax-2 controls multiple steps of urogenital development. Devel opment 1995; 121: 4057-4065.

18 Torres M, Gomez-Pardo M, Gruss P: Pax2 contributes to inner ear patterning and optic nerve trajectory. Development 1996; 122: 3381-3391.

19 Tellier A-L, Amiel J, Delezoide A-L et al: Expression of the PAX2 gene in human embyros and exclusion in the CHARGE association. Am J Med Genet 2000; 93: 85-88.

20 Gruss P, Walther C: Pax in development. Cell 1992; 69: 719-722. 